\title{
Associations between colostrum management, passive immunity, calf-related hygiene practices, and rates of mortality in preweaning dairy calves
}

\author{
J. Barry, ${ }^{1,2}$ E. A. M. Bokkers, ${ }^{2}$ D. P. Berry, ${ }^{1}$ I. J. M. de Boer ${ }^{2}$ J. McClure, ${ }^{3}$ and E. Kennedy ${ }^{1 *}$ \\ ${ }^{1}$ Teagasc, Animal and Grassland Research and Innovation Centre, Moorepark, Fermoy, Co. Cork, Ireland P61 C997 \\ ${ }^{2}$ Animal Production Systems group, Wageningen University and Research, PO Box 338, 6700 AH Wageningen, the Netherlands \\ ${ }^{3}$ Irish Cattle Breeding Federation, Bandon, Co. Cork, Ireland P72 X050
}

\section{ABSTRACT}

Calves are particularly vulnerable to health issues before weaning and experience high rates of mortality. Poor colostrum quality or substandard colostrum management, combined with poor hygiene, can increase disease susceptibility, contributing to elevated mortality rates. This study aimed to assess colostrum and calf management together with subsequent mortality rates in preweaning calves. Forty-seven Irish spring-calving, pasture-based dairy herds were enrolled in the study. To investigate whether colostrum and hygiene practices change as the calving season progresses, each farm was visited in both the first and last 6 wk of the calving season. The concentration of IgG in 250 colostrum samples and 580 calf serum samples was determined by radial immunodiffusion assay. Mean colostrum IgG concentration was $85 \mathrm{mg} / \mathrm{mL}$, and mean calf serum IgG concentration was 30.9 and $27.1 \mathrm{mg} / \mathrm{mL}$, respectively, in the first and last 6 wk of the calving season. Smaller herd size and younger age at sampling were associated with higher calf serum IgG concentration. Dairy breed calves were associated with higher serum IgG concentrations compared with beef breed calves; no association was detected based on sex. For feeding equipment hygiene, we assessed the presence of protein residues and found that hygiene levels tended to worsen from the first to the final $6 \mathrm{wk}$ of the calving season. We found no association between feeding equipment hygiene and herd size or 28-d calf mortality rate. Colostrum and calf management practices were not associated with either calf serum IgG concentration or 28-d calf mortality rate. We found that $\operatorname{IgG}$ concentration in colostrum produced in Irish dairy herds was generally good, although large variation existed, emphasizing the need

Received April 17, 2019

Accepted July 10, 2019

*Corresponding author: emer.kennedy@teagasc.ie for assessment of colostrum before feeding. Results also suggested that hygiene practices associated with calf rearing can be improved, particularly in the latter half of the calving season.

Key words: health, welfare, bull calves, serum immunoglobulin $\mathrm{G}$, commercial farms

\section{INTRODUCTION}

Seasonal, pasture-based dairy cow systems predominate in Ireland. These systems target a compact calving pattern in spring (February-April), where the objective is to have all cows calve in a 12 -wk period (Berry et al., 2013). This enables herd energy requirements to be synchronized with grass growth (Horan et al., 2004) but also results in a large number of calves being born in a short period. Such a peak in calf births can create challenges for animal management, health, and welfare.

Preweaning calves are particularly vulnerable to health issues such as enteritis and this is generally the age group in which bovine mortality rates are greatest (Murray et al., 2016; Ring et al., 2018). Colostrum quality and management, as well as calf-related hygiene practices (e.g., cleaning routine for feeding equipment, calving pens, group calf pens), can have a pronounced effect on dairy calf health and mortality (Godden, 2008; Uetake, 2013; Renaud et al., 2018).

The importance of colostrum management for bovines is derived from the lack of transfer of immunity from the maternal circulatory system to the fetus, because of the structure of the placental barrier (Chucri et al., 2010). Immunity must therefore be acquired passively from good quality colostrum (IgG concentration $\geq 50 \mathrm{mg} /$ mL; Weaver et al., 2000; McGuirk and Collins, 2004), the first milk produced after parturition (Barrington and Parish, 2001). Failure to achieve adequate transfer of passive immunity (TPI), measured as a serum IgG concentration $<10 \mathrm{mg} / \mathrm{mL}$ between $\geq 24 \mathrm{~h}$ and $\leq 7 \mathrm{~d}$ of life, increases the risk of disease (Weaver et al., 2000; Beam et al., 2009; Stilwell and Carvalho, 2011). Acute 
enteritis, one of the most common causes of calf mortality, is associated with colostrum management but also calf-related hygiene practices (Svensson et al., 2006; Klein-Jöbstl et al., 2014; Hotchkiss et al., 2015).

Failure to achieve adequate passive immunity can also affect performance later in life, through a reduction in growth rate (Furman-Fratczak et al., 2011), or first-lactation yield (DeNise et al., 1989). Understanding factors associated with successful TPI, therefore, is important. Three factors ultimately determine the success of TPI: (1) colostrum quality, commonly measured as IgG concentration (Garry et al., 1996); (2) colostrum management (e.g., timing of collection, timing of feeding, feeding method, storage; Weaver et al., 2000; Conneely et al., 2014); and (3) the volume of colostrum provided (Weaver et al., 2000). Although previous studies have assessed colostrum quality in research herds, limited information is available on colostrum quality in commercial dairy herds in Ireland. Recent studies that investigated management of colostrum on commercial Irish dairy farms have described it as suboptimal (Kennedy et al., 2014; Cummins et al., 2016). These studies, however, did not investigate associations between colostrum management practices and subsequent mortality rates. The objective of the present study was to assess colostrum and calf management practices on commercial Irish dairy farms and associated calf mortality rates.

\section{MATERIALS AND METHODS}

This study was carried out between February 4 and April 13, 2017. Ethical approval for the study was received from the Teagasc animal ethics committee (TAEC 102/2015), and procedure authorization (AE191132/P053) was granted by the Health Products Regulatory Authority of Ireland (HPRA). Experiments were undertaken in accordance with the Cruelty to Animals Act (Ireland 1876, as amended by European Communities regulations 2002 and 2005) and European Community Directive 86/609/EC.

\section{Herd Selection}

Dairy herds recruited into the study were located within an $80-\mathrm{km}$ radius of Teagasc Moorepark (the area most densely populated with dairy herds in Ireland), to minimize travel time and facilitate sample processing. Herds had to be subscribed to HerdPlus, a data management and reporting system operated by the Irish Cattle Breeding Federation (ICBF; Bandon, Co. Cork, Ireland). In Ireland, pasture-based, spring-calving production systems predominate, with the average herd containing 80 cows. Selected herds, therefore, fulfilled the criteria of operating a spring-calving, pasture-based system, with a minimum herd size of 70 cows. A letter inviting 188 identified herds was sent to each herd owner in an attempt to recruit them into the study. This letter outlined the objectives of the project, and reviewed the work involved, the expected outcomes, and the feedback participants would receive. Expressions of interest for inclusion in the study were collected by responding to a telephone number or email address, as outlined in the invitation letter. After $14 \mathrm{~d}$, a reminder letter was sent to those who had not yet responded, requesting a response. Forty-seven herd owners agreed to participate ( $25 \%$ response rate) and were contacted by telephone for details regarding the expected calving start date, specific farm location, and a suitable visit time (i.e., a.m. or p.m.) and date.

To investigate whether changes in colostrum and calf management occur as the calving season progresses, each farm was visited twice. Based on expected calving start date provided by each herd, a visit was made once, early in their calving season (i.e., within 6 wk of expected calving start date), and again in the latter half of the calving season (i.e., between wk 6 and 12 of expected calving start date). The first visits occurred between February 4 and March 11, and the second visits occurred between March 13 and April 13. Full consent was granted by participants to allow access to data on their herd through the HerdPlus database.

For each farm visit, 2 people were present: an individual experienced in assessing animal health and an individual who had received basic training in animal handling as well as conducting environmental measurements, as required for this study.

\section{Calf and Colostrum Management}

A calf welfare assessment protocol (Barry et al., 2019), which included an assessment of animal health, a management survey, and environmental measurements, was conducted during each farm visit. An interview was conducted with the principal calf manager to collect information on (1) calf management, such as timing of removal from the cow, timing of the first feed, feeding method used, and volume given; (2) colostrum management, which addressed timing of colostrum collection, colostrum storage, quality assessment, and use of externally sourced, or manufactured, colostrum.

In the second visit, the interview focused on potential areas where management practices might have changed (e.g., timing of calf removal from the cow after birth) as the number of calves present on farm increased and the associated workload intensified. 


\section{Hygiene Practices}

The interview also included questions on calf-related hygiene practices to determine cleaning routines for feeding equipment, calving areas, and calf pens (individual and groups pens). In each visit, trained personnel physically assessed hygiene to determine the effectiveness of such routines while also verifying answers given during the interview. The presence of surface protein residues on 2 feeding implements (e.g., esophageal tube feeders and group feeders) was assessed using 3M Clean-Trace surface protein plus test kits (3M, St. Paul, MN). Samples were collected by placing the swab at the center point of the feeding implement, or center point of liquid holding pouch for esophageal tube holders, and moving the swab once around the inner surface of the feeding implement. For automatic feeders, the swab was passed over the outer surface at the center point of the drinking teat. This is a semiquantitative assay that involves collecting a swab sample from the implement of interest. The swab is then placed in a chemical solution, which creates a reaction resulting in color formation. Color formation is related to the amount of proteins present, such as milk residues or biological contaminants (e.g., bacteria, fungi), which is measured on a 4-point reference scale, with 1 describing a low level of surface residue (i.e., good hygiene) and 4 describing a high level of surface residue (poor hygiene; Simpson et al., 2006).

\section{Colostrum Sample Collection}

Participants were given 6 empty sampling containers (120-mL polythene container; SGR Scientific, Swords, Ireland) during the first visit and asked to collect 6 colostrum samples at random from freshly calved cows. This number of samples per farm was based on a review of studies that investigated colostrum quality in commercial herds (Kehoe et al., 2007; Morrill et al., 2012) while also considering the relatively small dairy herd sizes in Ireland. Participants were required to record the identification number of each cow from which a colostrum sample was collected. This enabled information (e.g., breed, parity) to be collected on each animal via the HerdPlus database. Participants were asked to immediately freeze the samples $\left(-18^{\circ} \mathrm{C}\right)$ until collection during the second visit. Samples remained frozen up to the point of analysis for IgG concentration.

\section{Serum Sample Collection}

Any calf $\geq 24 \mathrm{~h}$ and $\leq 6 \mathrm{~d}$ of age, inclusive, at the time of the visit was blood sampled to assess serum IgG con- centration. This was undertaken to indicate whether adequate TPI had been achieved but also to examine the level of success of feeding practices, as answered in the interview. Blood samples were taken via the jugular vein using a plain serum tube $(10-\mathrm{mL}$ BD Vacutainer, $\mathrm{BD}$, Plymouth, UK). The identification number of each sampled calf was recorded, which allowed information on its breed and date of birth to be acquired from the ICBF database. Blood samples were kept on ice until returned to the research center, where they were refrigerated at $4^{\circ} \mathrm{C}$ for $24 \mathrm{~h}$ before serum separation by centrifugation $(3,000 \times g, 30 \mathrm{~min})$ at $4^{\circ} \mathrm{C}$. Following centrifugation, serum samples were collected and frozen at $-20^{\circ} \mathrm{C}$ pending determination of $\mathrm{IgG}$ concentration in a laboratory located at Teagasc Moorepark.

\section{Colostrum and Serum Sample Analysis}

Colostrum and serum samples were defrosted at $4^{\circ} \mathrm{C}$ for $24 \mathrm{~h}$ before analysis by radial immunodiffusion (RID) assay (Triple J Farms, Bellingham, WA). Each RID kit contained a 24-well test plate and 3 reference serum samples. Kits were stored at $4^{\circ} \mathrm{C}$ and removed 30 min before use. Colostrum samples were prepared at a 1:3 dilution using deionized water and serum samples were prepared at a 1:2 dilution using the same diluent. On each test plate, wells 1 to 3 contained the reference sera $(196,1,402$, and $1,976 \mathrm{mg} / \mathrm{dL})$, well 4 was blank, and the remaining wells contained serum or colostrum samples, all of which were tested in duplicate. Plates were incubated at room temperature $\left(20-24^{\circ} \mathrm{C}\right)$ for $24 \mathrm{~h}$. Diameters of the precipitate rings surrounding each well were measured to the nearest $0.01 \mathrm{~mm}$ using digital Vernier calipers. Ring diameter values of the 3 reference sera samples were squared and plotted against their known concentration to produce a standard reference curve. This was then used to determine the IgG concentration of the serum or colostrum samples present on the plate. Samples that produced a value beyond the range of the reference curve were diluted further and reanalyzed.

\section{Calf Mortality and Individual Cow 305-d Milk}

The mortality rate of calves born in participating herds in 2017 was provided by the ICBF. Also provided was the status (i.e., alive or deceased) of calves from which serum samples had been collected at the end of the calendar year in which they were born. For all deceased calves, the age at which mortality occurred was provided. Mean milk yield and 305-d geometric mean SCC for calendar year 2016 were provided by the ICBF for cows from which a colostrum sample was taken. 


\section{Data Editing}

To investigate statistical differences, categories were created using data set quartiles for the following variables: herd size, birth week of year for calves, age of calf at blood sampling, mean milk yield, and 305-d geometric mean SCC. Participant herd sizes were categorized as $<110,110-139,140-189$, and $\geq 190$ cows. The extent of assistance required at each calving was subjectively scored by farmers on a scale of 1 to 4 , where $1=$ no assistance provided; $2=$ manual assistance provided, without mechanical aid; $3=$ assistance provided, including use of mechanical aid; and $4=$ veterinary-assisted calving. Animals from which samples were collected were assigned a single breed descriptor. This was breedspecific for cows and sire breed-specific for calves (i.e., dairy or beef breed). For cows, if breed composition consisted of Holstein and Friesian only, then the animal was described as being Holstein-Friesian. If HolsteinFriesian represented the majority of breed composition of an animal, together with any another dairy breed (e.g., Jersey or Norwegian Red), then the animal was defined as a Holstein-Friesian cross. For calves, those sired by a dairy bull were classified as "dairy" and those sired by a beef breed were classified as "beef." Calves were categorized based on the calendar week of the year when born: within the first 6 wk, wk 6-7.9, wk 8-9.9, and during or after wk 10 of 2017. Age of the calf at blood sampling was categorized as 1-2 d, 3-4 d, $5 \mathrm{~d}$, and $6 \mathrm{~d}$ old. Mean yield for the 2016 milking season was categorized, based on quartiles of the complete data set, as $<5,000 \mathrm{~L}, 5,000-6,000 \mathrm{~L},>6,000-7,000 \mathrm{~L}$, and $>7,000$ L. Similarly, individual cow 305-d geometric mean SCC for the calendar year 2016 was categorized as $<50,000$, 50,000-74,999, 75,000-150,000, and $>150,000$ cells $/ \mathrm{mL}$.

\section{Statistical Analyses}

All dependent variables followed a normal distribution pattern. Significant associations were confirmed at $P<0.05$; in each model, interactions were examined between significant variables and least squares means assessed. Risk factors associated with continuous variables measured at 2 (repeated) time points (i.e., calf serum IgG concentration) were assessed using linear mixed models in PROC MIXED (SAS version 9.4; SAS Institute Inc., Cary, NC). The risk factors associated with calf mortality rates (excluding stillbirths), which had no repeated measure, were assessed using fixed effects regression models in PROC GLM (SAS version 9.4). For the binary trait of calf mortality, the logit of the probability of a calf dying when serum IgG concentration was below the recommended threshold (i.e.,
$<10 \mathrm{mg} / \mathrm{mL}$ ) was determined using logistic regression in PROC GENMOD (SAS version 9.4), assuming a binomial distribution of the error term.

For colostrum IgG concentration, fixed effects considered in the model were herd size, calving early or late in the season, cow breed, parity, milk yield, and SCC; herd was treated as a random effect with a covariance structure assumed among records within herd. For serum IgG concentration, fixed effects considered were herd size, hygiene of feeding equipment, calf and colostrum management practices, calf breed, sex, birth week of year, age at blood sampling, and the extent of assistance required at calving; visit number was treated as a repeated effect and a covariance structure assumed among records within visit. For calf $28-d$ mortality rate, fixed effects considered were calf serum IgG concentration, herd size, hygiene of calf feeding equipment, and management practices.

\section{RESULTS}

\section{Colostrum IgG Concentration}

Mean colostrum IgG concentration, as determined by RID assay, was $85.1(\mathrm{SD}=51.6) \mathrm{mg} / \mathrm{mL}$. In total, $21 \%$ of the samples had an IgG concentration less than the recommended threshold of $50 \mathrm{mg} / \mathrm{mL}$. No association was observed with the independent variables of herd size, calving week of year, breed, parity, milk yield, or SCC.

\section{Serum IgG Concentration and Calf Mortality}

Mean (SD) calf serum IgG concentrations in visit 1 and 2 were 30.9 (13.4) mg/mL and 27.1 (14.0) mg/mL, respectively, and did not differ from each other. Mean (SD) serum IgG concentration for both visits was 29.3 (13.3) $\mathrm{mg} / \mathrm{mL}$ for males and 30.3 (14.1) $\mathrm{mg} / \mathrm{mL}$ for female calves, and did not differ from each other. Herd size $(P<0.01)$, breed $(P<0.05)$, and age at blood sampling $(P<0.01)$ were all associated with serum IgG concentration. An inverse relationship existed between serum IgG concentration with both herd size (Figure 1) and age at blood sampling (Figure 2). A significant interaction between calf breed group and serum $\operatorname{IgG}$ concentration existed based on calf sex. Mean serum IgG concentration was highest in female dairy calves $(31.2 \mathrm{mg} / \mathrm{mL})$ and lowest in female beef calves $(26.0$ $\mathrm{mg} / \mathrm{mL}$ ). Mean calf mortality rates at different time points are summarized in Table 1. Mortality among calves with a serum IgG $<10 \mathrm{mg} / \mathrm{mL}$ was not different $(P=0.18)$ from that of calves with a serum $\operatorname{IgG}$ concentration $\geq 10 \mathrm{mg} / \mathrm{mL}$. 


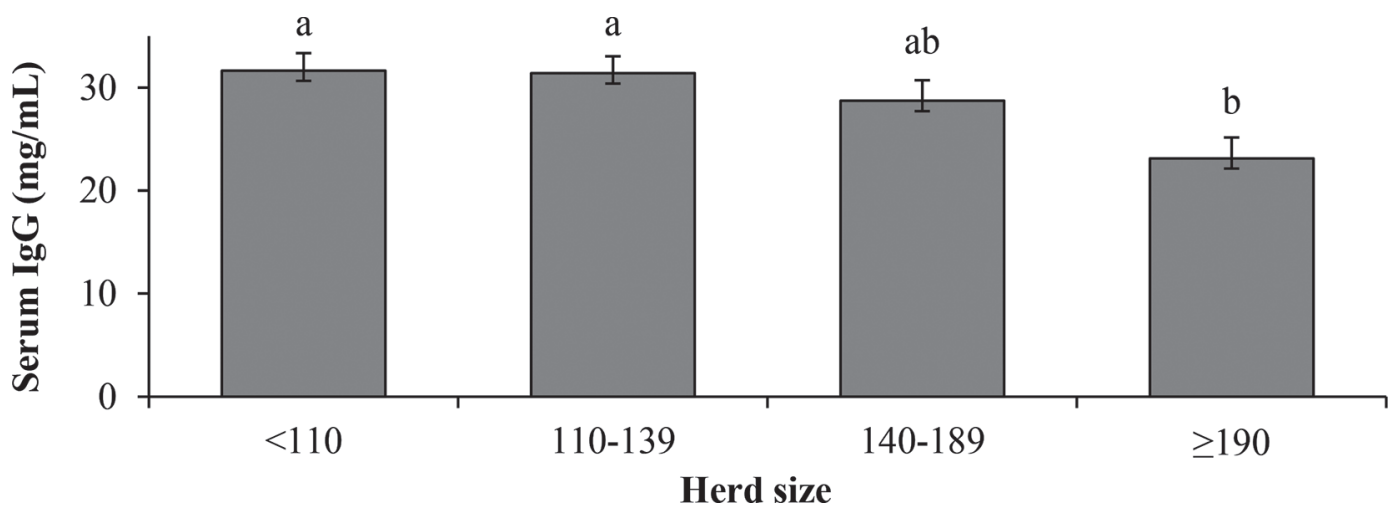

Figure 1. Least squares means $( \pm 1 \mathrm{SE}$ ) for serum $\operatorname{IgG}$ concentration in calves from 1 to $6 \mathrm{~d}$ old, determined by radial immunodiffusion assay, by herd size (number of cows). Bars with different letters $(\mathrm{a}, \mathrm{b})$ indicate a significant difference $(P<0.05)$ in means.

\section{Hygiene Practices}

The median hygiene scores of the feeding implements in visit 1 and visit 2 are reported in Table 2. Hygiene tended to decline from visit 1 to visit $2(P=$ $0.07)$, whereas no association was identified between hygiene score and herd size $(P=0.19)$. Better hygiene (i.e., lower hygiene score) tended to be associated with higher calf serum $\operatorname{IgG}$ concentration $(P=0.07)$. No association $(P=0.26)$ was detected between hygiene score and 28-d mortality rate. Responses for method and frequency of hygiene practices applied during each visit are outlined in Table 3. Hygiene practices were not associated with serum IgG concentration or 28 -d calf mortality rate.

\section{Calf Management and Colostrum Feeding}

Participant responses regarding management practices related to collection, storage, source, and quality assessment of colostrum are reported in Table 4. No association was identified for colostrum management practices and calf serum IgG concentration or 28-d mortality rate. Responses on colostrum feeding and calf management during the first and last 6 wk of the calving season, for male and female calves, are reported in Table 5. Similarly, colostrum feeding and calf management responses were not associated with either calf serum IgG concentration or 28-d mortality rate.

\section{DISCUSSION}

The importance of colostrum management for calf health has been well established (Jaster, 2005; Godden, 2009; Erickson, 2015), with much work conducted internationally to assess colostrum quality on commercial dairy farms (Gulliksen et al., 2008; Morrill et al., 2012; Phipps et al., 2017). Limited information, however, is available on colostrum quality and calf-related hygiene practices on commercial dairy farms in Ireland. This study aimed to assess colostrum and calf management practices, as well as passive immunity levels on com-

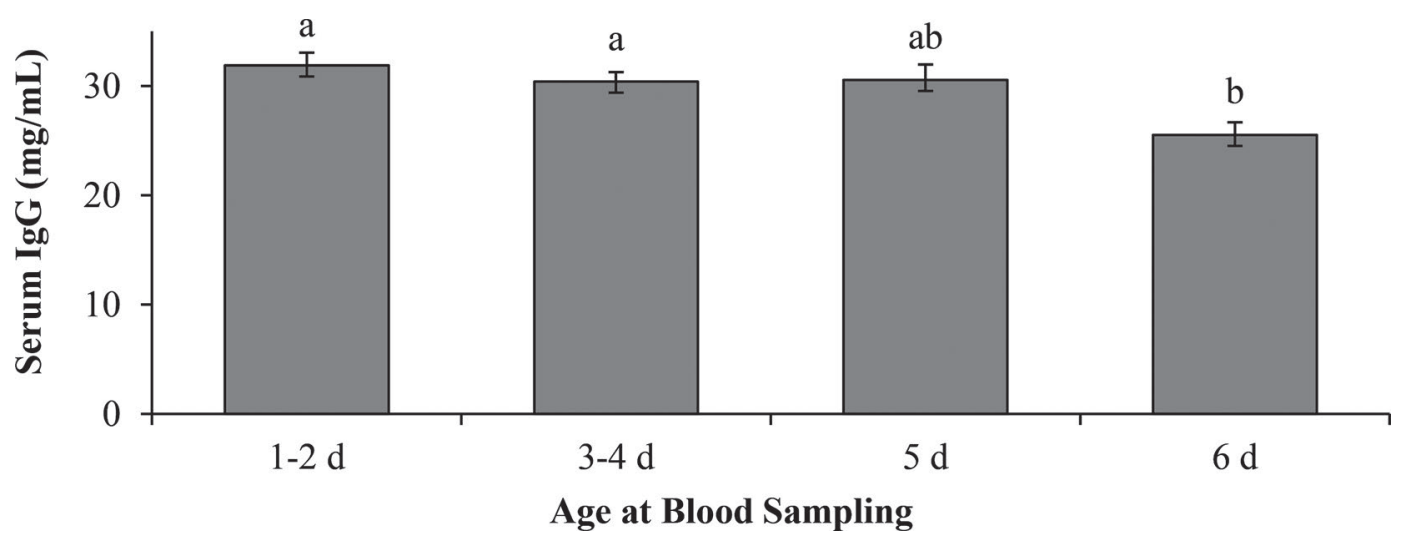

Figure 2. Least squares means ( $\pm 1 \mathrm{SE}$ ) for serum IgG concentration in calves from 1 to $6 \mathrm{~d}$ old, determined by radial immunodiffusion assay, located across 47 commercial Irish dairy farms. Bars with different letters (a, b) indicate a significant difference $(P<0.05)$ in means. 
Table 1. Mean mortality rate, from birth to 6 time points during the first year of life, of all calves born in 2017 on 47 commercial Irish dairy farms (SD in parentheses)

\begin{tabular}{lc}
\hline Time point from birth & Cumulative mortality rate (\%) \\
\hline $3 \mathrm{~d}$ & $3.57(2.45)$ \\
$7 \mathrm{~d}$ & $4.43(2.48)$ \\
$28 \mathrm{~d}$ & $5.86(3.12)$ \\
$3 \mathrm{mo}$ & $7.34(3.44)$ \\
$6 \mathrm{mo}$ & $8.28(3.72)$ \\
$12 \mathrm{mo}$ & $9.31(4.29)$ \\
\hline
\end{tabular}

mercial Irish dairy farms, while also investigating associations with calf mortality.

\section{Colostrum IgG Concentration}

Of colostrum samples collected in this study, $21 \%$ were below the recommended threshold of $50 \mathrm{mg} /$ $\mathrm{mL}$ (Weaver et al., 2000). This is greater than values reported in previous studies assessing colostrum quality in dairy cows. Conneely et al. (2013), for example, reported that $4 \%$ of samples collected from 4 Irish dairy research herds were below the threshold, whereas Quigley et al. (2013) found that $16 \%$ of samples collected from 7 commercial US dairy farms were below the threshold. In a Norwegian study similar to the present study, where 1,250 colostrum samples were collected by
Table 2. Mean hygiene score for calf feeding implements, determined using surface residues test kits, and scored on a 4 -point scale ${ }^{1}$

\begin{tabular}{|c|c|c|}
\hline \multirow[b]{2}{*}{ Feeding implement } & \multicolumn{2}{|c|}{ Mean hygiene score } \\
\hline & Visit 1 & Visit 2 \\
\hline Automatic feeder & $1.0(\mathrm{n}=3)$ & $1.0(\mathrm{n}=3)$ \\
\hline Bottle and teat feeder & $2.5(\mathrm{n}=2)$ & $2.3(\mathrm{n}=2)$ \\
\hline Multi-teat feeder & $2.3(\mathrm{n}=64)$ & $2.9(\mathrm{n}=61)$ \\
\hline Individual teat feeder & $2.4(\mathrm{n}=13)$ & $2.1(\mathrm{n}=7)$ \\
\hline Esophageal tube feeder & $4.0(\mathrm{n}=1)$ & $4.0(\mathrm{n}=1)$ \\
\hline
\end{tabular}

${ }^{1}$ Where 1 represents low residue levels and 4 represents high residue levels, assessed in the first (visit 1) and last (visit 2) $6 \mathrm{wk}$ of the calving season.

dairy farmers across 119 herds, Gulliksen et al. (2008) reported that $57.8 \%$ of these samples were below the threshold. Some of the colostrum samples in that study were collected from cows that had already nursed their calf, however, in which case a lower IgG concentration would be expected (Foley and Otterby, 1978; Godden, 2008). In the present study, if the proportion of calf serum samples below the threshold for adequate TPI was similar to that of colostrum samples identified as being poor quality (IgG concentration of $<50 \mathrm{~g} / \mathrm{L}$ ), it could indicate that colostrum quality was influencing passive immunity. The percentage of calf serum samples below the recommended threshold was lower $(8 \%)$ than

Table 3. Responses from calf managers across 47 commercial Irish dairy farms on preferred frequency and method for specific calf-related hygiene practices during the first (visit 1) and last (visit 2) 6 wk of the calving season

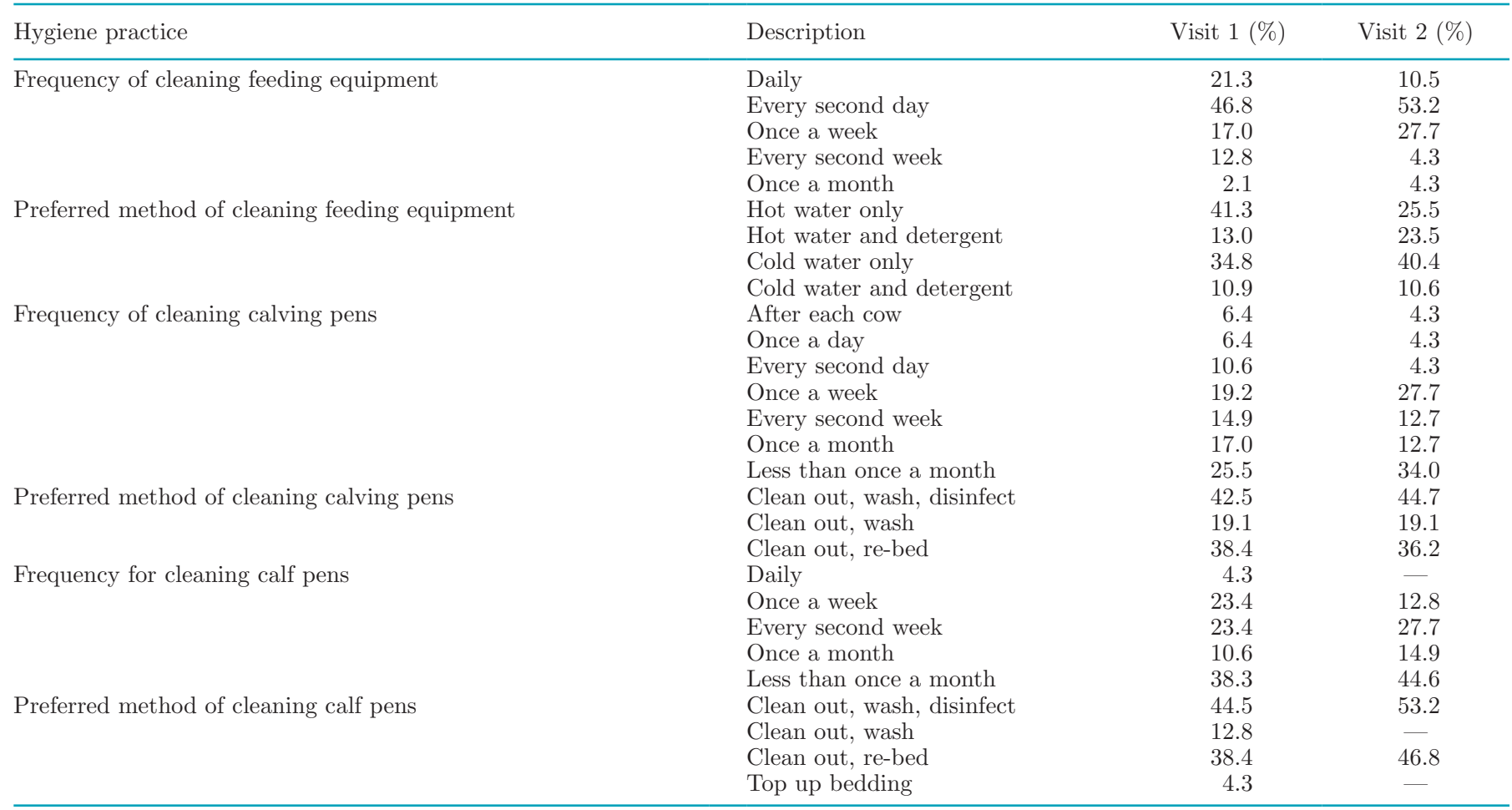


Table 4. Responses from calf managers across 47 commercial Irish dairy farms on management practices related to collection, storage, source, and quality assessment of colostrum

\begin{tabular}{llc}
\hline \multirow{2}{*}{ Colostrum management } & Description & $\begin{array}{c}\text { Response } \\
(\%)\end{array}$ \\
\hline Colostrum collection timing & $<2 \mathrm{~h}$ & 33.0 \\
& Next scheduled milking & 63.8 \\
& $<24 \mathrm{~h}$ & 1.1 \\
Is colostrum stored? & Not collected & 2.1 \\
& Yes & 91.5 \\
Where is the storage location? & No & 8.5 \\
& Fridge & 12.8 \\
Time from collection to feeding & Freezer & 63.8 \\
& Room temperature & 23.4 \\
& $<2 \mathrm{~h}$ & 59.6 \\
& $2-3 \mathrm{~h}$ & 10.6 \\
& $<4 \mathrm{~h}$ & 4.3 \\
Testing colostrum quality & $4-6 \mathrm{~h}$ & 2.1 \\
Source colostrum externally & $>6 \mathrm{~h}$ & 2.1 \\
& Not collected/stored & 21.3 \\
Using colostrum replacement products & Yes & 12.8 \\
& No & 87.2 \\
& Yes & 14.9 \\
& No & 85.1 \\
& Yes & 12.8 \\
\end{tabular}

that of colostrum samples (21\%), which supports the hypothesis that the sampling procedure, carried out by participants, could in some cases have influenced colostrum IgG concentration (Hopkins and Quigley, 1997).

In the present study, a relatively high mean IgG concentration in colostrum was identified; however, considerable variation existed therein, ranging from 4 to $324 \mathrm{mg} / \mathrm{mL}$. Previous studies have reported smaller variability in colostrum IgG concentration (7-159 mg/ mL: Quigley et al., 2013; 4-235 mg/mL: Gulliksen et al., 2008; 13-256 mg/mL: Conneely et al., 2013). Although sampling procedure would contribute to some

Table 5. Responses from calf managers across 47 commercial Irish dairy herds on colostrum feeding and calf management practices, in the first (visit 1) and last (visit 2) 6 wk of the calving season, and for female and male calves

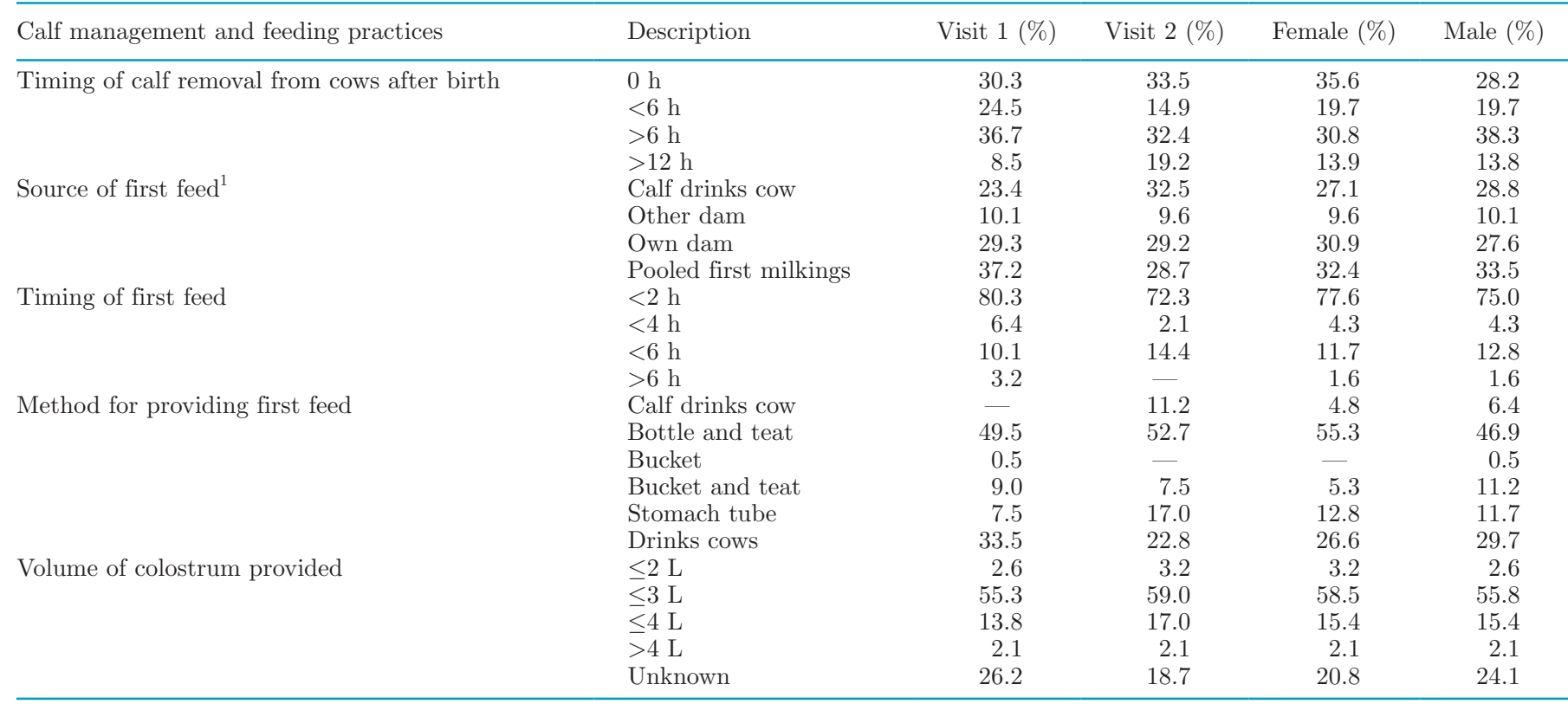

"Calf drinks cow" refers to farmers allowing calves to drink directly from the cow without providing a feed. "Other dam" refers to colostrum being collected from a cow and then hand fed to a calf (born from a different cow). "Own dam" refers to farmers collecting colostrum from the cow and then hand feeding it to the calf. 
of the variation identified, much would be naturally occurring due to variation in immune system strength and functionality (Hurley, 2003), as well as the known heritable genetic variation in colostrum IgG concentration in dairy cows (Conneely et al., 2013). The extent of the variation identified in Irish dairy herds highlights the need for assessment of colostrum quality before feeding, a practice currently applied on less than $15 \%$ of farms (Table 4).

\section{Serum IgG Concentration}

Mean calf serum IgG concentration at both visit 1 $(30.9 \mathrm{mg} / \mathrm{mL})$ and visit $2(27.1 \mathrm{mg} / \mathrm{mL})$ was almost 3 times that of the threshold for adequate TPI, with less than $10 \%$ of calf serum samples being below the threshold. Given the intense labor requirement during the calving period in seasonal calving systems, a reduction in serum $\operatorname{IgG}$ concentration in calves born later in the season would have been expected. We, however, found no difference in IgG concentration in calf serum samples collected early or late in the calving season. Although this study is unique in that herds were visited on 2 separate occasions, studies that collected serum samples at single time points reported a lower mean serum $\mathrm{IgG}$ concentration (21.6 $\mathrm{mg} / \mathrm{mL}$ : Lombard et al., 2016; $22.0 \mathrm{mg} / \mathrm{mL}$ : Chigerwe et al., 2015). The relatively high serum IgG concentration in the present study could be attributed to the high mean IgG content of colostrum, which would facilitate the achievement of high levels of passive immunity (Weaver et al., 2000).

Although we identified a statistical difference between mean serum calf $\operatorname{IgG}$ concentrations in dairy and beef calves, both breed groups had mean values more than 2 times the recommended threshold. Breed and serum IgG were also statistically different based on sex. Female dairy calves, which would be considered to have the highest monetary value, had the highest serum IgG concentration, whereas female beef calves, which would be of a lower monetary value, had the lowest. Both groups had a serum IgG concentration more than twice that of the threshold for passive immunity; however, perceived monetary value could be influencing the actual management received. In terms of dairy calf management, previous studies have demonstrated that preferential treatment can be provided to female calves (Fecteau et al., 2002; Shivley et al., 2016, 2018). The difference in mortality rates between male and female dairy calves observed nationally in Ireland (DAFM 2015, 2016) suggests that management practices could differ by calf sex. Although management practices could vary based on sex and breed, serum IgG concentration indicated no difference in successful TPI based on sex. This suggests that on commercial Irish dairy farms, all calves are managed in a way that facilitates achievement of adequate TPI, regardless of sex.

Although we identified a negative association between serum IgG concentration and herd size, biologically similar rates of passive immunity were achieved. Previous studies investigating associations between calf health and herd size have also identified negative associations (Lance et al., 1992; Silva del Río et al., 2007; Gulliksen et al., 2009). The negative association identified in the present study could be attributable to the use of labor-saving measures in larger herds. One such measure is the use of pooled colostrum feeding, which was practiced by over $30 \%$ of participants in the present study. Pooling colostrum of unknown quality can reduce the overall IgG concentration (Weaver et al., 2000) and increase the risk of calf exposure to colostrum-borne pathogens (Godden, 2009). Given the high frequency with which pooled colostrum feeding is practiced, further investigation is warranted on pooled colostrum to determine the level and extent of immunity achieved when using this feeding strategy.

Following colostrum feeding, serum IgG concentration peaks at approximately $24 \mathrm{~h}$ and declines gradually thereafter (Shivley et al., 2016; Tóthová et al., 2016). The association identified in this study between serum IgG concentration and age at blood sampling was therefore as expected. A reduction of approximately $20 \%$, or $1.28 \mathrm{mg} / \mathrm{mL}$ per day, over a 5 -d period was identified in serum $\operatorname{IgG}$ concentration in calves from $\mathrm{d}$ 1 to 6 of life (31.9 vs. $25.5 \mathrm{mg} / \mathrm{mL} \operatorname{IgG}$ ). This rate of antibody depletion is similar to that identified in dairy calves by Shivley et al. (2018), who reported a depletion rate of $0.71 \mathrm{mg} / \mathrm{mL} \operatorname{IgG}$ per day in early life. This equates to a reduction rate of approximately $16 \%$ over a 5 -d period, given the mean reported value of $21.6 \mathrm{mg} /$ $\mathrm{mL}$ IgG. Knowing the rate at which antibody depletion occurs is important for herd owners and veterinarians alike, because it can enable retrospective calculations to be made to determine whether adequate TPI was likely achieved.

Failure to find a difference in mortality based on the calf serum IgG threshold of $10 \mathrm{mg} / \mathrm{mL}$ indicates that this threshold may need to be revised, particularly for Irish dairy systems. The $10 \mathrm{mg} / \mathrm{mL}$ IgG threshold is widely accepted as the cut-off point for passive immunity, as applied in many research studies. Some studies, however, suggest that this threshold may need to be adjusted for different countries or regions and also different production system types (i.e., seasonal calving systems). Wittum and Perino (1995) found that for calves raised in a beef production environment, the risk of mortality was greater when calf serum $\operatorname{IgG}$ concentration was $<8 \mathrm{mg} / \mathrm{mL}$ compared with those $>16 \mathrm{mg} /$ mL. In Holstein heifer calves, Robison et al. (1988) re- 
ported a 2-fold increase in mortality among calves with serum IgG concentration $<12 \mathrm{mg} / \mathrm{mL}$. These studies, along with the present study, suggest that further work is required to re-evaluate the cut-off points for passive immunity among calves in seasonal calving systems.

\section{Hygiene Practices}

No association was detected in the present study between serum $\operatorname{IgG}$ concentration and calf mortality. Similarly, no association was detected between serum IgG concentration and either hygiene scores or hygiene practices. Poor hygiene practices for feeding equipment can result in bacterial contamination of colostrum, and numerous studies have reported a negative association between colostrum bacterial content and TPI (James et al., 1981; Staley and Bush, 1985). Godden (2009) reported that feeding colostrum with low bacterial levels resulted in higher serum $\operatorname{IgG}$ concentration and reduced rates of morbidity in calves; however, no reference was made to the effect on calf mortality. The mean colostrum IgG concentration in the present study was greater than that of Godden (2009) (85.1 vs. 61.1 $\mathrm{mg} / \mathrm{mL}$ ), and thus could be counteracting any effect of contamination through antigen binding (Indyk et al., 2008).

\section{Calf Management and Colostrum Feeding}

No associations were found between calf management and either serum IgG concentration or mortality rate. Similarly for colostrum feeding practices, no association was detected with either serum IgG concentration or mortality rate. Although the likelihood of mortality occurring in calves with a serum $\operatorname{IgG}$ concentration $<10 \mathrm{mg} / \mathrm{mL}$ was not significantly different from that of calves with a serum IgG concentration $\geq 10 \mathrm{mg} /$ $\mathrm{mL}$, numerically, the risk was almost double. Similar studies, however, have reported associations between management practices and mortality rates (Shivley et al., 2018), as well as associations between serum IgG concentration and mortality rates (Lora et al., 2018). Failure to detect such associations in the present study could be due to management data referring to general practices and not to the specific management received by individual calves from which a serum sample was collected.

Although adjustments to management and feeding practices were identified as the calving season progressed, this did not affect the level of passive immunity achieved in the calves. Failure to measure colostrum quality on the majority of farms is an issue of concern, which could contribute to the occurrence of failed TPI. Pooled colostrum feeding and allowing calves to drink directly from the cow, which are both commonly practiced on Irish dairy farms, could have negative implications for calf health (Weaver et al., 2000) but also disease transfer within herds.

\section{Study Limitations}

Field studies, and particularly those conducted onfarm, generally operate with certain limitations. In this study, the number of samples collected and the collection method used were influenced by the nature of the study. Before commencement of the study, we conducted a power calculation to determine the subset required per herd, and we selected age criteria for blood-sampled calves (i.e., $\geq 1 \mathrm{~d}$ and $\leq 6 \mathrm{~d}$ old). This limited the availability of suitable calves, particularly during the second visit, when the number and frequency of cows calving had declined. For collection of colostrum samples, farmers were instructed to collect samples from freshly calved cows at random; however, a potential selection bias could exist. This was given careful consideration before beginning the experiment and, as there were no recent data for colostrum quality on commercial dairy farms, we considered it important to benchmark current colostrum quality. It would be preferable to have exercised greater control over cow selection and the sampling procedure but this would have required a prolonged presence on-farm, which would not be feasible. Also, it was important that colostrum samples were collected from freshly calved cows, a point emphasized to participants, and preselecting cows for sampling could have influenced results; for example, in cases where a preselected cow had calved unsupervised and the participant proceeded to collect a sample without knowing the time since parturition.

Overcoming such issues could prove difficult given the number of restrictive factors associated with largescale studies on calf health in seasonal calving systems (i.e., herds calving simultaneously, short calving season length, age restrictions for sampled calves, relatively small herd sizes). The present study was conducted in a single calving season and covered a limited geographical area. Future studies could be conducted over several calving seasons and limit enrollment to larger herds or cover a larger geographical area.

\section{CONCLUSIONS}

Our results showed that colostrum management on commercial Irish dairy farms is of a high standard, with a $>90 \%$ success rate for achieving adequate TPI. Serum IgG concentration was higher in calves born in smaller herds ( $<110$ cows), but mean serum IgG concentration across all herd sizes exceeded the recommended 
threshold $(\geq 10 \mathrm{mg} / \mathrm{mL})$. Colostrum quality in Irish dairy herds is generally good; however, considerable variation exists in colostrum IgG concentration. Negative implications associated with such variation could be overcome by assessing colostrum quality, a practice currently conducted on less than $15 \%$ of Irish dairy farms. Hygiene practices related to calf feeding equipment can be improved, and particularly during the final 6 weeks of the calving season. This could reduce the risk of bacterial contamination of colostrum, and further increase the rate of passive immunity achieved on commercial dairy farms.

\section{ACKNOWLEDGMENTS}

The authors thank all those who participated in this study, and Ian Hogan and Clare Ryan from the Limerick Regional Veterinary Laboratory for their help with sample analyses. The authors acknowledge the funding support by the Teagasc Walsh Fellowship funding scheme. The authors declare no conflict of interest.

\section{REFERENCES}

Barrington, G. M., and S. M. Parish. 2001. Bovine neonatal immunology. Vet. Clin. North Am. Food Anim. Pract. 17:463-476.

Barry, J., E. Kennedy, R. Sayers, I. J. M. De Boer, and E. A. M. Bokkers. 2019. Development of a welfare assessment protocol for dairy calves from birth through to weaning. Anim. Welf. 28:331-344. https://doi.org/10.7120/09627286.28.3.331.

Beam, A. L., J. E. Lombard, C. A. Kopral, L. P. Garber, A. L. Winter, J. A. Hicks, and J. L. Schlater. 2009. Prevalence of failure of passive transfer of immunity in newborn heifer calves and associated management practices on US dairy operations. J. Dairy Sci. 92:3973-3980.

Berry, D. P., J. Kearney, K. Twomey, and R. Evans. 2013. Genetics of reproductive performance in seasonal-calving dairy cattle production systems. Ir. J. Agric. Food Res. 52:1-16.

Chigerwe, M., J. V. Hagey, and S. S. Aly. 2015. Determination of neonatal serum immunoglobulin $\mathrm{G}$ concentrations associated with mortality during the first 4 months of life in dairy heifer calves. J. Dairy Res. 82:400-406.

Chucri, T. M., J. M. Monteiro, A. R. Lima, M. L. B. Salvadori, J. R. K. Junior, and M. A. Miglino. 2010. A review of immune transfer by the placenta. J. Reprod. Immunol. 87:14-20.

Conneely, M., D. Berry, R. Sayers, J. Murphy, I. Lorenz, M. Doherty, and E. Kennedy. 2013. Factors associated with the concentration of immunoglobulin $\mathrm{G}$ in the colostrum of dairy cows. Animal $7: 1824-1832$

Conneely, M., D. P. Berry, J. P. Murphy, I. Lorenz, M. L. Doherty, and E. Kennedy. 2014. Effect of feeding colostrum at different volumes and subsequent number of transition milk feeds on the serum immunoglobulin G concentration and health status of dairy calves. J. Dairy Sci. 97:6991-7000.

Cummins, C., D. Berry, R. Sayers, I. Lorenz, and E. Kennedy. 2016. Questionnaire identifying management practices surrounding calving on spring-calving dairy farms and their associations with herd size and herd expansion. Animal 10:868-877.

DAFM (Department of Agriculture, Food and the Marine). 2015. AgriFood and Biosciences Institute (AFBI) All-Island Animal Disease Surveillance Report 2015. Accessed Jan. 14, 2016. https://www .afbini.gov.uk/sites/afbini.gov.uk/files/publications/aiadsr2015 _30-11-16\%20LR_Designer\%204.pdf.
DAFM (Department of Agriculture, Food and the Marine). 2016 Agri-Food and Biosciences Institute (AFBI) All-Island Animal Disease Surveillance Report 2016. Accessed Jan. 14, 2016. https:/ /www.agriculture.gov.ie/media/migration/animalhealthwelfare/ labservice/rvlreports/AIDSRReport016230118.pdf.

DeNise, S. K., J. Robison, G. Stott, and D. Armstrong. 1989. Effects of passive immunity on subsequent production in dairy heifers. J. Dairy Sci. 72:552-554.

Erickson, P. 2015. Colostrum: Its effect on cattle health and performance. J. Dairy Sci. 98(Suppl. 1):26 (Abstr.)

Fecteau, G., P. Baillargeon, R. Higgins, J. Paré, and M. Fortin. 2002. Bacterial contamination of colostrum fed to newborn calves in Québec dairy herds. Can. Vet. J. 43:523.

Foley, J. A., and D. E. Otterby. 1978. Availability, storage, treatment, composition, and feeding value of surplus colostrum: A review. J. Dairy Sci. 61:1033-1060.

Furman-Fratczak, K., A. Rzasa, and T. Stefaniak. 2011. The influence of colostral immunoglobulin concentration in heifer calves' serum on their health and growth. J. Dairy Sci. 94:5536-5543.

Garry, F. B., R. Adams, M. Cattell, and R. Dinsmore. 1996. Comparison of passive immunoglobulin transfer to dairy calves fed colostrum or commercially available colostral-supplement products. J. Am. Vet. Med. Assoc. 208:107.

Godden, S. M. 2008. Colostrum management for dairy calves. Vet. Clin. North Am. Food Anim. Pract. 24:19-39.

Godden, S. M. 2009. Improving passive transfer of immunoglobulins in calves. II: Interaction between feeding method and volume of colostrum fed. J. Dairy Sci. 92:1758-1764.

Gulliksen, S. M., K. I. Lie, T. Løken, and O. Østerås. 2009. Calf mortality in Norwegian dairy herds. J. Dairy Sci. 92:2782-2795.

Gulliksen, S. M., K. I. Lie, L. Sølverød, and O. Østerås. 2008. Risk factors associated with colostrum quality in Norwegian dairy cows. J. Dairy Sci. 91:704-712.

Hopkins, B. A., and J. Quigley. 1997. Effects of method of colostrum feeding and colostrum supplementation on concentrations of immunoglobulin $\mathrm{G}$ in the serum of neonatal calves. J. Dairy Sci. 80:979-983.

Horan, B., J. Mee, M. Rath, P. O'Connor, and P. Dillon. 2004. The effect of strain of Holstein-Friesian cow and feeding system on reproductive performance in seasonal-calving milk production systems. Anim. Sci. 79:453-467.

Hotchkiss, E., S. Thomson, B. Wells, E. Innes, and F. Katzer. 2015. Update on the role of cryptosporidiosis in calf diarrhoea. Livest. (Lond) 20:316-322.

Hurley, W. 2003. Immunoglobulins in mammary secretions. Pages 421-447 in Advanced Dairy Chemistry - 1 Proteins. Springer, New York, NY.

Indyk, H. E., J. W. Williams, and H. A. Patel. 2008. Analysis of denaturation of bovine IgG by heat and high pressure using an optical biosensor. Int. Dairy J. 18:359-366.

James, R. E., C. E. Polan, and K. A. Cummins. 1981. Influence of administered indigenous microorganisms on uptake of [iodine-125] $\gamma$-globulin in vivo by intestinal segments of neonatal calves. J. Dairy Sci. 64:52-61.

Jaster, E. H. 2005. Evaluation of quality, quantity, and timing of colostrum feeding on immunoglobulin G1 absorption in jersey calves. J. Dairy Sci. 88:296-302.

Kehoe, S. I., B. Jayarao, and A. Heinrichs. 2007. A survey of bovine colostrum composition and colostrum management practices on Pennsylvania dairy farms. J. Dairy Sci. 90:4108-4116.

Kennedy, A. E., E. F. O'Doherty, N. Byrne, J. O'Mahony, E. Kennedy, and R. G. Sayers. 2014. A survey of management practices on Irish dairy farms with emphasis on risk factors for Johne's disease transmission. Ir. Vet. J. 67:27.

Klein-Jöbstl, D., M. Iwersen, and M. Drillich. 2014. Farm characteristics and calf management practices on dairy farms with and without diarrhea: A case-control study to investigate risk factors for calf diarrhea. J. Dairy Sci. 97:5110-5119.

Lance, S. E., G. Miller, D. Hancock, P. Bartlett, L. E. Heider, and M. Moeschberger. 1992. Effects of environment and management 
on mortality in preweaned dairy calves. J. Am. Vet. Med. Assoc. 201:1197-1202.

Lombard, J. E., C. B. Shivley, and N. Urie. 2016. Factors associated with colostrum quality and passive transfer status of dairy heifer calves on US dairy operations. J. Anim. Sci. 94:592.

Lora, I., F. Gottardo, B. Contiero, B. D. Ara, L. Bonfanti, A. Stefani, and A. Barberio. 2018. Associations between passive immunity and health status of dairy calves under 30 days of age. Prev. Vet. Med. 152:12-15.

McGuirk, S. M., and M. Collins. 2004. Managing the production, storage, and delivery of colostrum. Vet. Clin. North Am. Food Anim. Pract. 20:593-603.

Morrill, K. M., E. Conrad, A. Lago, J. Campbell, J. Quigley, and H. Tyler. 2012. Nationwide evaluation of quality and composition of colostrum on dairy farms in the United States. J. Dairy Sci. 95:3997-4005

Murray, C. F., L. Fick, E. Pajor, H. Barkema, M. Jelinski, and M. Windeyer. 2016. Calf management practices and associations with herd-level morbidity and mortality on beef cow-calf operations. Animal 10:468-477.

Phipps, A. J., D. Beggs, A. Murray, P. Mansell, and M. Pyman. 2017. Factors associated with colostrum immunoglobulin G concentration in northern-Victorian dairy cows. Aust. Vet. J. 95:237-243.

Quigley, J. D., A. Lago, C. Chapman, P. Erickson, and J. Polo. 2013 Evaluation of the Brix refractometer to estimate immunoglobulin G concentration in bovine colostrum. J. Dairy Sci. 96:1148-1155.

Renaud, D. L., D. Kelton, S. LeBlanc, D. Haley, and T. Duffield. 2018. Calf management risk factors on dairy farms associated with male calf mortality on veal farms. J. Dairy Sci. 101:1785-1794.

Ring, S. C., J. McCarthy, M. Kelleher, M. Doherty, and D. Berry. 2018. Risk factors associated with animal mortality in pasture-based, seasonal-calving dairy and beef herds. J. Anim. Sci. 96:35-55.

Robison, J. D., G. H. Stott, and S. K. DeNise. 1988. Effects of passive immunity on growth and survival in the dairy heifer. J. Dairy Sci. 71:1283-1287.
Shivley, C. B., J. Lombard, N. Urie, D. Haines, R. Sargent, C. Kopral, T. Earleywine, J. Olson, and F. Garry. 2018. Preweaned heifer management on US dairy operations: Part II. Factors associated with colostrum quality and passive transfer status of dairy heifer calves. J. Dairy Sci. 101:9185-9198.

Shivley, C., N. Urie, and J. Lombard. 2016. Management of dairy bull calves on US dairy operations. J. Anim. Sci. 94:581.

Silva del Río, N. S., S. Stewart, P. Rapnicki, Y. Chang, and P. M. Fricke. 2007. An observational analysis of twin births, calf sex ratio, and calf mortality in Holstein dairy cattle. J. Dairy Sci. 90:1255-1264.

Simpson, W. J., J. L. Archibald, and C. J. Giles. 2006. Protocol for assessing the sensitivity of hygiene test systems for live microorganisms and food residue. UK Report 120906, 27 July 2006. Cara Technology Limited, Leatherhead, UK.

Staley, T. E., and L. J. Bush. 1985. Receptor mechanisms of the neonatal intestine and their relationship to immunoglobulin absorption and disease. 1985. J. Dairy Sci. 68:184-205.

Stilwell, G., and R. C. Carvalho. 2011. Clinical outcome of calves with failure of passive transfer as diagnosed by a commercially available IgG quick test kit. Can. Vet. J. 52:524.

Svensson, C., A. Linder, and S. O. Olsson. 2006. Mortality in Swedish dairy calves and replacement heifers. J. Dairy Sci. 89:4769-4777.

Tóthová, C., O. Nagy, G. Kováč, and V. Nagyová. 2016. Changes in the concentrations of serum proteins in calves during the first month of life. J. Appl. Anim. Res. 44:338-346.

Uetake, K. 2013. Newborn calf welfare: A review focusing on mortality rates. Anim. Sci. J. 84:101-105.

Weaver, D. M., J. W. Tyler, D. C. VanMetre, D. E. Hostetler, and G. M. Barrington. 2000. Passive transfer of colostral immunoglobulins in calves. J. Vet. Intern. Med. 14:569-577.

Wittum, T. E., and L. J. Perino. 1995. Passive immune status at postpartum hour 24 and long-term health and performance of calves. Am. J. Vet. Res. 56:1149-1154. 